\title{
Multifunctional Antenna with Reconfigurable Ultra-Wide Band Characteristics
}

\author{
Asha VERMA, Manoj SINGH PARIHAR \\ Dept. of Electronics \& Communication Engineering, PDPM-Indian Inst. of Information Technology, Design and \\ Manufacturing Jabalpur (PDPM-IIITDMJ), Jabalpur, India \\ asha.v04@gmail.com,mscareiit@gmail.com
}

Submitted May 27, 2016 / Accepted September 27, 2016

\begin{abstract}
In this paper a multifunctional antenna is presented which offers an ultra-wideband (UWB) operation, an UWB operation with two switchable notches and reconfigurable dual-band operation for WiMAX and WLAN applications, respectively. Total seven functions/states could be achieved from a single antenna using an electronic switching. The antenna uses dual slots on the ground plane to provide a wide bandwidth, ranging from $3.1 \mathrm{GHz}$ to $10.6 \mathrm{GHz}$. U-shaped slot and C-shaped printed strip in the ground are used to generate two notches at $3.6 \mathrm{GHz}$ (WiMAX) and $5.2 \mathrm{GHz}$ (WLAN/ WiFi) bands, respectively. Moreover, four parasitic strips are added in the feed side to make antenna functional at either $3.6 \mathrm{GHz}$ or $5.2 \mathrm{GHz}$ or both. Total five PIN diodes are required to obtain seven operations from the proposed antenna. Seven structures are fabricated and measured to verify the seven states and results are found in good agreement with estimated results obtained from the simulation.
\end{abstract}

\section{Keywords}

Reconfigurable antenna, UWB antenna, C-shaped strip, PIN diode, parasitic strip

\section{Introduction}

Reconfigurable antennas have received significant attention in recent year for modern wireless communication system due to their multi-functional properties. Multiband/wideband antennas are very much required in present communication systems for covering multiple applications such as WiMAX, WLAN, GPS, GSM, UMTS, DCS, PCS, and LTE within a single system. Conventionally, multiband applications require separate receiving/transmitting antennas at different operating frequencies with different radiation characteristics. For multi-band operation different techniques have been adopted such as adding parasitic strips to create additional resonances [1-3]. The use of multiple antennas to cover multiple bands would require a large physical area and subsequently system complexity and costwill increase manifold. A single wide band antenna could also serve the same purpose, but it may not provide a better selectivity between the adjacent bands which results in poor signal to noise ratio (SNR). Moreover, all applications might not be activated all the time, hence the wide band/multi-band antennas would create an electromagnetic interference (EMI) to other systems from those applications. Though, using a reconfigurability concept in an antenna, all applications could be accommodated into a single circuit capable of switching between different applications whenever they required/activated. Thus the concept of reconfigurability would make the system more compact, less complex and cost effective. To achieve reconfigurability, various switching techniques have been adopted such as PIN diodes, RF-MEMS switches, and photoconductive switches.

These techniques modify the physical shape of the antenna electronically; consequently the surface current distribution gets altered, which in turn modifies the operating characteristics of an antenna such as operating frequency and radiation pattern [4-6]. UWB antennas should have the properties of wide impedance bandwidth (3.1 GHz-10.6 GHz), constant gain, linear phase, stable radiation pattern, low spectral power density, which makes UWB system suitable for short range high speed communication [7], [8]. Microstrip fed wide slot antennas might be a good selection to obtain an ultra-wide impedance bandwidth due to less interaction with surface waves and could be easily integrated with active devices [9].

Due to wide bandwidth of UWB system, it is interfered by nearby existing communication systems such as WiMAX and WLAN. However, this interference could be minimized by creating notched response at these frequency bands. Notch structure could be realized by inserting U-shaped, C-shaped, $\pi$-shaped slot, stepped impedance stub (SIS), stepped impedance resonators (SIR), SIS loaded hexagon stepped impedance resonators (HSIR), rectangular split ring, defected microstrip structure band stop filter (DMS-BSF), open ended T-shaped stub, etching spur slot, and half and quarter-wavelength strip in the form of resonator, either in the ground plane or in radiating plane itself [10-13], [15-20]. In most of these works, authors have reported reconfigurable UWB operation with single notch 
or multiple notches. In [21], reconfigurability is obtained through physical rotation of an antenna to achieve reconfigurable dual frequency operation along with UWB operation without notches.

In this paper, an UWB reconfigurable antenna with three slots in the ground planes and parasitic strips on the feed side is proposed to provide seven operations/states in different bias conditions. The proposed antenna is excited by a $50 \Omega$ microstrip feed line. To the best of our belief, seven modes of operation using a single reconfigurable antenna which could achieve UWB response with notches and dual resonating modes have not been reported so far.

The basic design taken from [14], consists of dual slots (wide and small rectangular) etched on the ground plane to provide a fixed lower ultra-wide band response (2.17-6.25 GHz) with dual notches in the WiMAX band. In this work the design has been modified substantially to cover the complete UWB response with reconfigurable characteristics.

The work is organized as follows: In Sec. 2, the design of the proposed reconfigurable antenna and its parametric analysis is presented. Section 3 shows simulated and measured reflection coefficients, radiation characteristics and gain of the proposed antenna. Finally the work is concluded in Sec. 4.

\section{Antenna Design}

The proposed layout of UWB antenna for reconfigurable dual notched and dual band operation is illustrated in Fig. 1, including DC biasing circuitry. It consists of rectangular dual slots (wide and smaller rectangular slots), U-shaped slot and C-shaped segmented metal strip in the ground plane. The wide rectangular slot resonates at a lower cutoff frequency of UWB due to its large size, which elongates current path. Similarly the small rectangular slot generates minimum current path thus operates at higher cutoff frequency. The areas of the wide and small rectangular slots control the lower and upper cutoff frequencies of the UWB response, respectively [14].

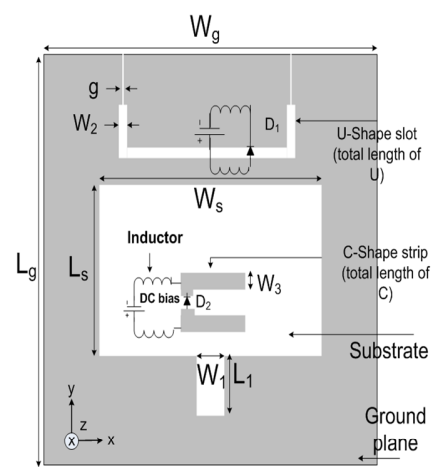

(a)

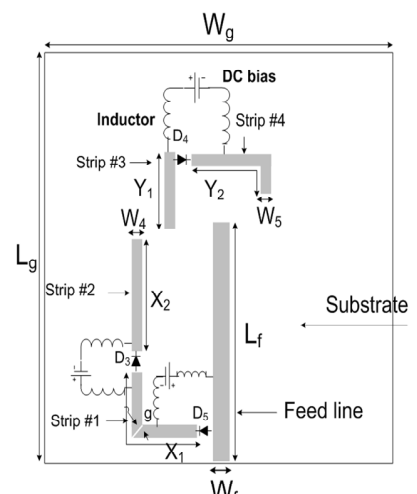

(b)
Fig. 1. Layout of the proposed reconfigurable UWB antenna (a) Top layer. (b) Bottom layer.

\begin{tabular}{|c|c|c|c|c|c|c|c|c|c|c|}
\hline $\begin{array}{c}\text { Ground } \\
\text { plane } \\
\text { (Top } \\
\text { layer) }\end{array}$ & $\mathrm{L}_{\mathrm{g}}$ & $\mathrm{W}_{\mathrm{g}}$ & $\mathrm{L}_{\mathrm{s}}$ & $\mathrm{W}_{\mathrm{s}}$ & $\mathrm{L}_{1}$ & $\mathrm{~W}_{1}$ & $\mathrm{~W}_{2}$ & $\mathrm{~W}_{3}$ & $\mathrm{U}_{1}$ & $\mathrm{U}_{2}, \mathrm{U}_{3}$ \\
\cline { 2 - 10 } & 40 & 14 & 27 & 6.4 & 4 & 1 & 2 & 24 & 6 \\
\hline $\begin{array}{c}\text { Feed } \\
\text { plane } \\
\text { (Bottom) }\end{array}$ & $\mathrm{L}_{\mathrm{f}}$ & $\mathrm{W}_{\mathrm{f}}$ & $\mathrm{X}_{1}$ & $\mathrm{X}_{2}$ & $\mathrm{Y}_{1}$ & $\mathrm{Y}_{2}$ & $\mathrm{~W}_{4}$ & $\mathrm{~W}_{5}$ & $\mathrm{~g}$ & $\mathrm{C}_{1}, \mathrm{C}_{2}$ \\
\cline { 2 - 10 } & 23.2 & 2.2 & 10 & 16 & 7 & 13 & 2 & 2 & 0.1 & 11 \\
\hline
\end{tabular}

Tab. 1. Optimized design parameters.

As shown in Fig. 1(a), U-shaped slot provides rejection at $3.6 \mathrm{GHz}$ frequency, whereas $\mathrm{C}$-shaped segmented strip is used to reject WLAN $(5.2 \mathrm{GHz})$ band. It is noted that the lengths of U-shaped slot and C-shaped strip are approximately $0.5 \lambda_{g}$ and act as resonating circuit at respective notch frequencies (3.6 and $5.2 \mathrm{GHz}$ ). As shown in Fig. 1(b), four parasitic copper strips are used on the feed side to allow the same antenna to radiate in either $3.6 \mathrm{GHz}$ (WiMAX) or $5.2 \mathrm{GHz}$ (WLAN) band or in both bands. These strips generate additional current paths and act as radiating resonators at $3.6 \mathrm{GHz}$ and $5.2 \mathrm{GHz}$. The overall size of the antenna (including substrate) is $\left(40 \times 40 \mathrm{~mm}^{2}\right)$. It is fabricated on an RT/Duroid5870 Rogers substrate with dielectric constant $\varepsilon_{\mathrm{r}}=2.55$ and thickness $h_{\mathrm{S}}=0.77 \mathrm{~mm}$.

The proposed structure is simulated in Finite Integral Technique (FIT) based CST Microwave Studio EM simulator. The optimized dimensions $(\mathrm{mm})$ of the proposed antenna are revealed in Tab. 1. The length of slot ' $U$ ' could be varied to control the notch frequency of WiMAX band, while WLAN notch can be controlled by the length of segmented C-shaped metal strip. Frequency $3.6 \mathrm{GHz}$ of single band antenna could be obtained by connecting metal strips $\# X_{1}$ and $\# X_{2}$ to the feed line. The WLAN band is achieved when only strip $\# X_{1}$ is connected (strip $\# X_{2}$ is disconnected) to the feed line. The role of strip $Y_{1}$ and $Y_{2}$ is to provide $\mathrm{WiFi}$ band in dual-band mode (strips $\# X_{1}$ and $\# X_{2}$ are connected to feed line for WiMAX band in this case). To validate the above statements parametric study is carried out using CST microwave studio. The deviation of lengths of U-shaped slot and C-shaped strip and their effect on frequency response is shown in Fig. 2. It is established that changing the lengths of U-shaped slot OR C-shaped strip, notch frequency could be varied as desired. Theoretically, the lengths $U$ and $C$ of slot and strip can be calculated as

$$
U, C=\frac{c}{2 \cdot f_{3.6}, f_{5.2} \cdot \sqrt{\varepsilon_{\mathrm{eff}}}}
$$

where $f$ is the respective notch frequency, $c$ is the velocity of light in free space, and $\varepsilon_{\text {eff }}$ is the effective dielectric constant.

The effect of variation of length $X$ on frequency response is shown in Fig. 3. Here the length $X$ is considered as an addition of $X_{1}$ and $X_{2}$. It is seen that length $X$ could be varied to shift the lower frequency $(3.6 \mathrm{GHz})$ of the dual band antenna while to attain upper frequency band $5.2 \mathrm{GHz}$ 


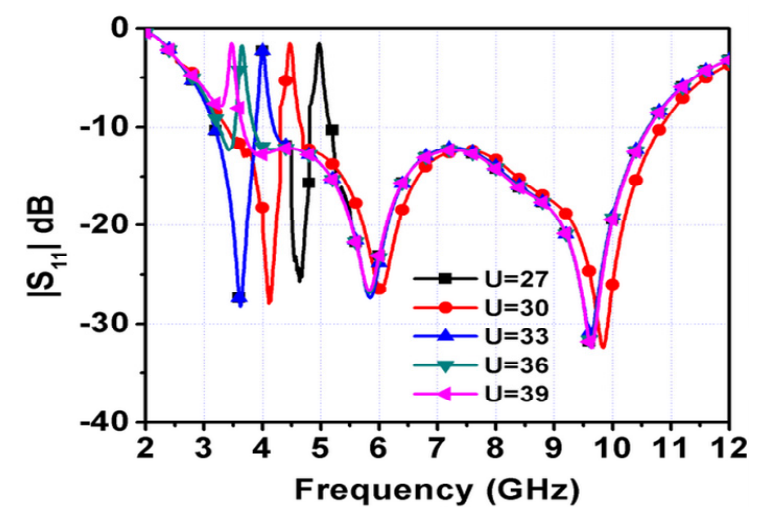

(a)

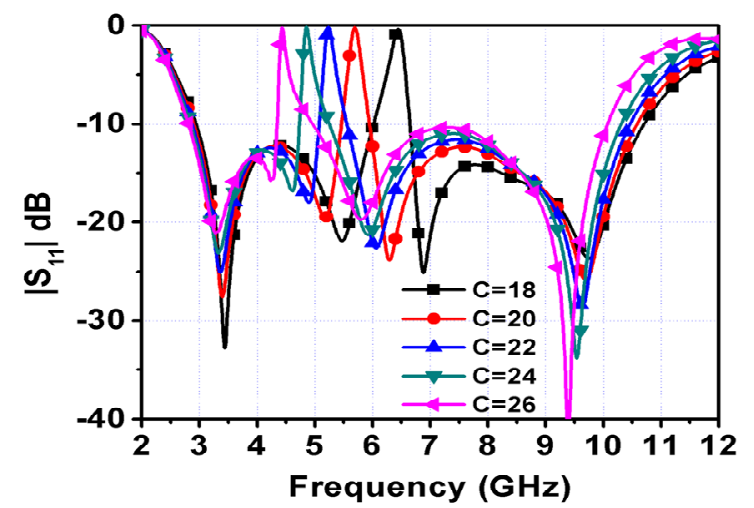

(b)

Fig. 2. Reflection coefficient versus frequency plot for variation in: (a) the lengths of U-shaped slot, (b) the length of $\mathrm{C}$-shaped segmented metal strip.

the length $X$ is altered as $X_{2}$. The second resonance which is not so strong, is observed at $7.0 \mathrm{GHz}$; it is because of loading strips $Y_{1}$ and $Y_{2}$, used to achieve $5.2 \mathrm{GHz}$ operating band (WLAN).

To realize reconfigurability in the proposed antenna, five HPND-4005 PIN diodes $\left(\mathrm{D}_{1}-\mathrm{D}_{5}\right)$, with appropriate biasing are embedded at different locations. All diodes are biased independently and RF to DC isolation is provided by creating a small gap $g$ of $0.1 \mathrm{~mm}$. In the EM simulation switches/diodes are realized using the metal strips. The ON state (ideal ON) of the diode is realized by inserting a metal strip of $\left(0.4 \times 0.2 \mathrm{~mm}^{2}\right)$ at the physical position of the diode and it is removed to realize diode's OFF state (ideal OFF). For full wave EM simulation, five discrete/ lumped ports are placed in CST at the physical locations of diodes. After post processing, $6 \times 6 \mathrm{~S}$-matrix file generated and imported in Advanced Design System (ADS) for cosimulation because the CST simulation does not take into account the packaging effect of the diode or complex RLC model [4].

As shown in Fig. 4, spice model of actual HPND4005 PIN diode will be connected to the five ports (2-6) of the model exported from an EM simulator. The first port will be used for RF input excitation. The spice parameters PIN diode model used in ADS are: $V_{\text {th }}=1 \mathrm{~V}, R_{\mathrm{S}}=4.7 \Omega$, $C_{\mathrm{j}}=0.017 \mathrm{pF}$. All diodes are biased through separate DC supplies.
The capacitors and inductors of $10 \mathrm{pF}$ and $50 \mathrm{nH}$ are used to provide DC and RF isolation, respectively [5], [6], [11-13]. To limit the DC current a series resistor of $100 \Omega$ is used with all diodes. To activate each PIN diode, a bias



Fig. 3. Reflection coefficient versus frequency variation plot for different values of parasitic strip length $X\left(X_{1}+X_{2}\right)$.

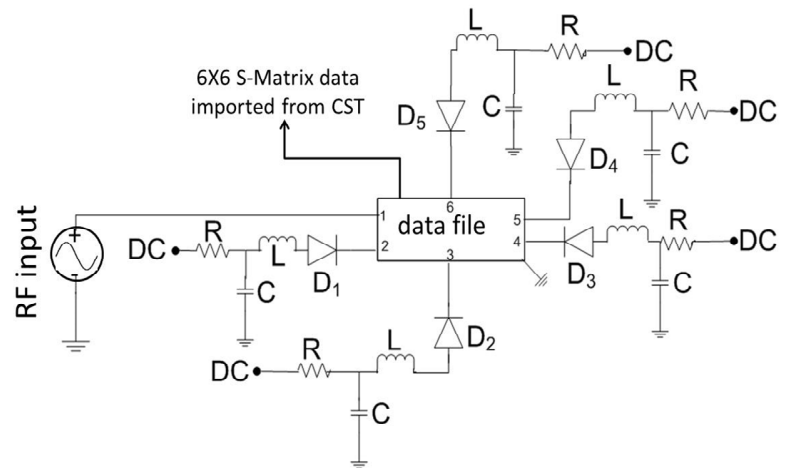

Fig. 4. Full wave circuit model of the proposed antenna.

\begin{tabular}{|l|c|c|c|c|c|c|}
\hline State & $\mathrm{D}_{1}$ & $\mathrm{D}_{2}$ & $\mathrm{D}_{3}$ & $\mathrm{D}_{4}$ & $\mathrm{D}_{5}$ & Operation \\
\hline State-1 & ON & OFF & OFF & OFF & OFF & UWB (3.1-10.6 GHz) \\
\hline State-2 & OFF & OFF & OFF & OFF & OFF & $\begin{array}{c}\text { UWB with single notch at } \\
3.6 \mathrm{GHz} \text { (WiMAX) }\end{array}$ \\
\hline State-3 & ON & ON & OFF & OFF & OFF & $\begin{array}{c}\text { UWB with single notch at } \\
5.2 \text { GHz (WLAN) }\end{array}$ \\
\hline State-4 & OFF & ON & OFF & OFF & OFF & $\begin{array}{c}\text { UWB operation with dual } \\
\text { 5.2 GHz (WiMAX \& } \\
\text { WLAN) }\end{array}$ \\
\hline State-5 & ON & OFF & ON & OFF & ON & $\begin{array}{c}\text { Resonance at 3.6 GHz } \\
\text { (WiMAX) }\end{array}$ \\
\hline State-6 & ON & OFF & OFF & ON & ON & $\begin{array}{c}\text { Resonance at 5.2 GHz } \\
\text { (WLAN) }\end{array}$ \\
\hline & ON & OFF & ON & ON & ON & $\begin{array}{c}\text { Dual-band response at 3.6 } \\
\text { GHz and at 5.2 GHz } \\
\text { (WiMAX \& WLAN) }\end{array}$ \\
\hline
\end{tabular}

Tab. 2. Different combination of diode states. 

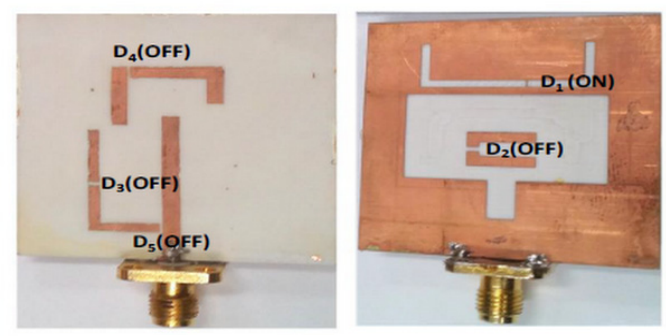

State-1 (UWB)

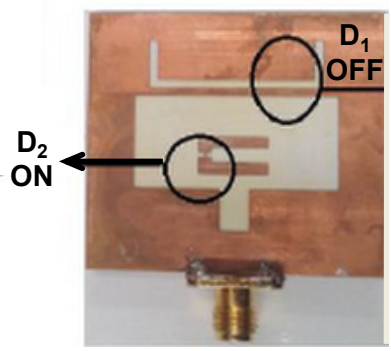

State-4

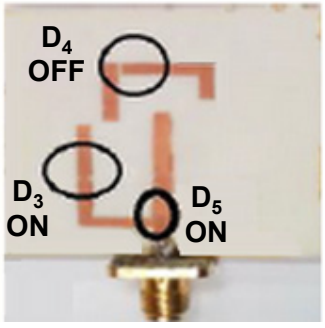

State-5



State-2

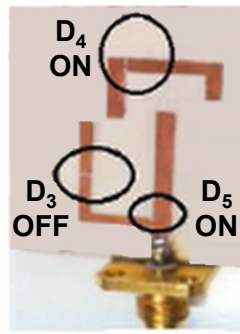

State-6



State-3



State-7

Fig. 5. Photographs of the reconfigurable antenna for seven different states.

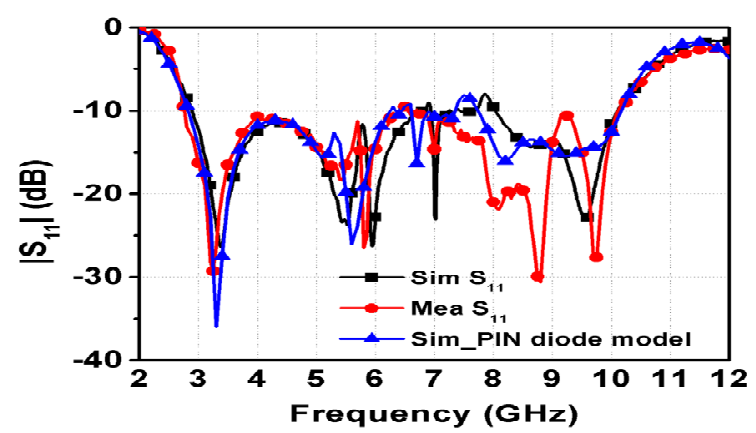

(a)

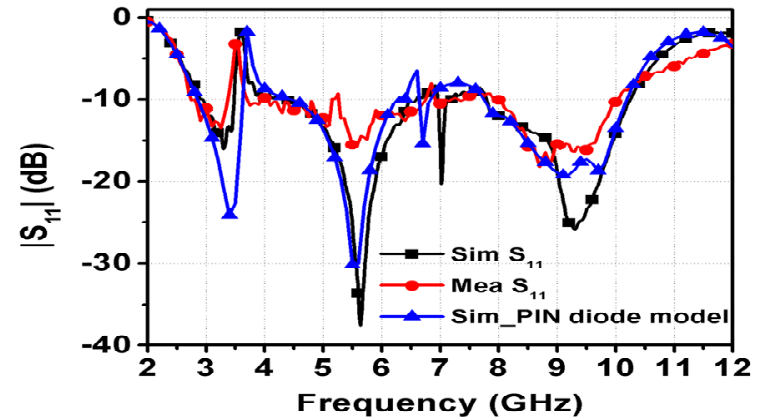

(b)

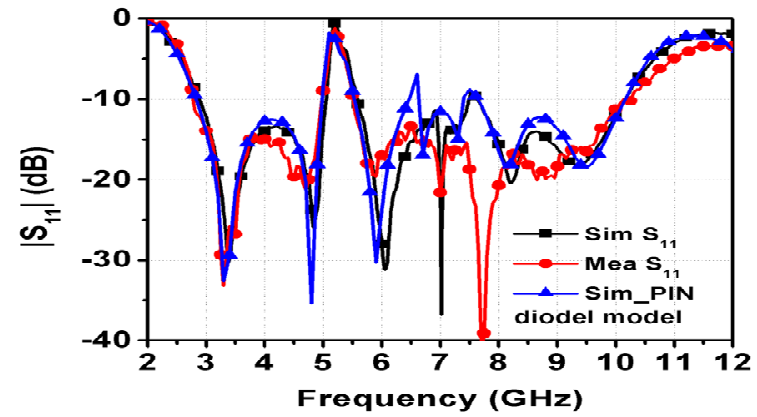

(c)

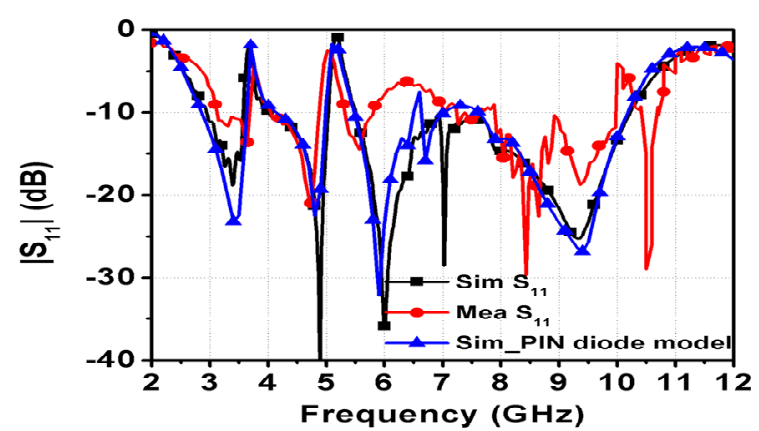

(d)

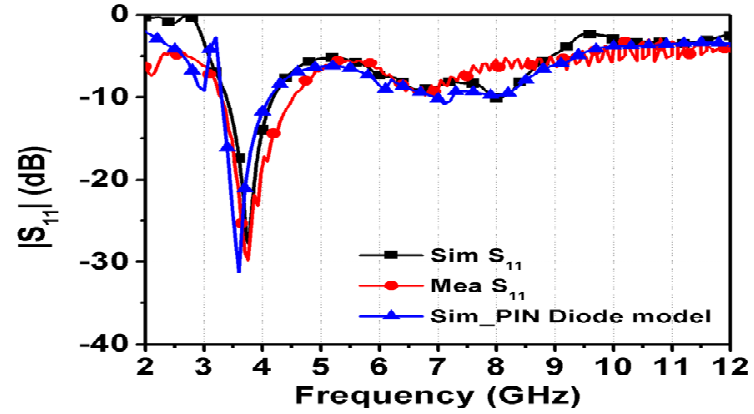

(e)

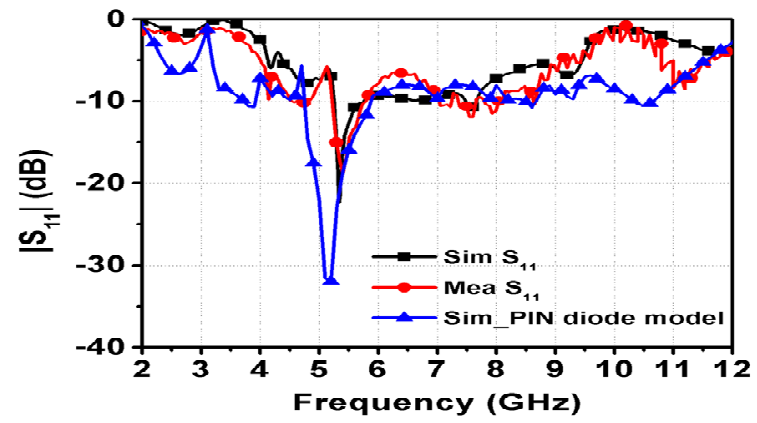

(f) 


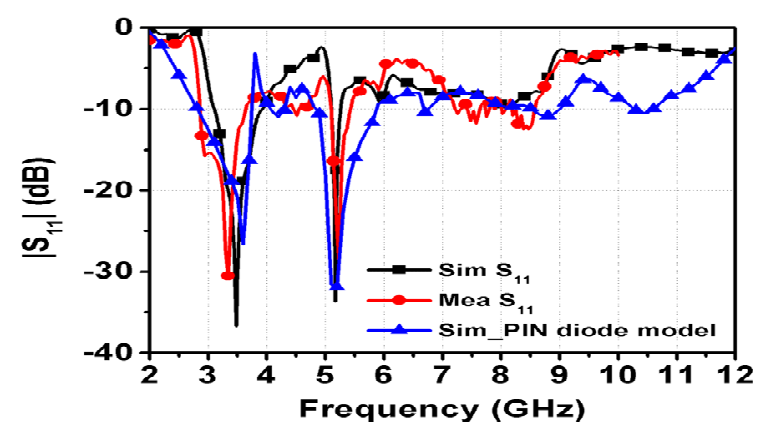

(g)

Fig. 6. Reflection coefficient of the proposed antenna: (a) State-1, (b) State-2, (c) State-3, (d) State-4, (e) State-5, (f) State-6, and (g) State-7.

current of $10 \mathrm{~mA}$ is applied. Seven states of the proposed antenna are summarized in Tab. 2, under different bias conditions. Due to unavailability of actual PIN diodes, seven distinct circuits are printed with ideal switches (metal strips) to verify the seven states of the proposed circuit and it is found that the operating principle is verified using ideal switches and the results obtained with the actual PIN diode model. Fabricated prototypes of seven states (state-1 to 7) are shown in Fig. 5. The circuits were fabricated using the LPKF PCB prototyping machine. Fabricated circuits were tested using Agilent's Vector Network Analyzer E5071C for its frequency response in seven states.

\section{Simulation and Measured Results}

Frequency responses of the simulated and measured reflection coefficient in seven states are shown in Figs. 6. Here measurement results are compared from two simulators: (a) from CST where metal strips are used to realize the ideal ON and they are removed in OFF states, (b) from ADS where spice model of HPND-4005 is used. It is depicted that measurement results are in good agreement with simulations in the lower UWB band. Though a small deviation is seen in the simulation results obtained from CST and ADS, which may be due to the difference in the switching methods being used. Additionally, the measured results in the Figs. 6 (a) and (d) are different with the simulated ones. The reason is that, as mentioned above, seven states of the proposed antenna are obtained with seven different printed antennas (Fig. 5).

One thing which is very common in the measured results shown in Figs. 6 (a) and (d) is that both states have used the same bottom layer and it was observed that the gaps to realize an OFF state of the switch/diode were not fabricated properly in this layer due to the conventional lithography process. It could also be observed that the difference is reasonably significant in the upper UWB band rather lower UWB region. This is quite obvious because at higher frequency any deviation in the physical dimensions becomes more critical. Furthermore, as shown in Fig. 6(a), the measured impedance bandwidth is $7.4 \mathrm{GHz}$ (2.9 to $10.3 \mathrm{GHz}$ ) covering the UWB spectrum nearly. Figures $6(\mathrm{~b}-\mathrm{d})$ show the UWB response with single and dual notches. The first notch occurred at $3.5 \mathrm{GHz}$ with rejection level of $-1.9 \mathrm{~dB}$. The second notch is obtained at $5.2 \mathrm{GHz}$ with $-1.1 \mathrm{~dB}$ rejection. Figures $6(\mathrm{e}-\mathrm{g})$ show the responses of the proposed antenna in single mode and dual-band mode operations. The radiating single mode is achieved at $3.75 \mathrm{GHz}$ with an impedance bandwidth $(-10 \mathrm{~dB})$ of $1 \mathrm{GHz}$ which covers the entire WiMAX band. The second single radiating mode is obtained at $5.4 \mathrm{GHz}$ with a bandwidth of $0.5 \mathrm{GHz}$, sufficient to cover WLAN band.

Figure 7 shows the surface currents in seven states. In state-1 shown in Fig. 7(a) at 3.1 GHz, large current is observed around the bigger slot that is quite understandable because it decides the lower cutoff for UWB response. In state-2 and 3, Figs. 7(b) and (c), current is mostly flowing in U-shaped slot and C-shaped metal strip which confirm their rejection behavior at respective frequencies. Figure 7(d) shows that in state-5 current is concentrated in the strip $X_{1}+X_{2}$, responsible for single band operation at 3.6 GHz or $5.2 \mathrm{GHz}$, respectively. In Fig. 7(e) and (f) current is flowing largely in $X_{1}+X_{2}$ and $Y_{1}$ and $Y_{2}$ which provides radiation at $3.65 \mathrm{GHz}$ and $5.2 \mathrm{GHz}$ respectively in dual-band mode $\left(X_{1}\right.$ and $X_{2}$ are combined to radiate at $3.6 \mathrm{GHz}$ in this mode).



(a)

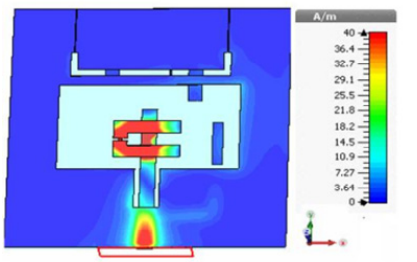

(c)

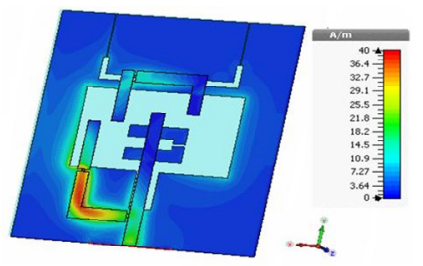

(e)

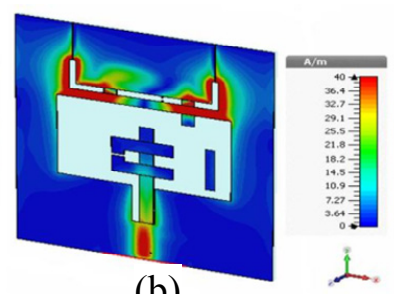

(b)

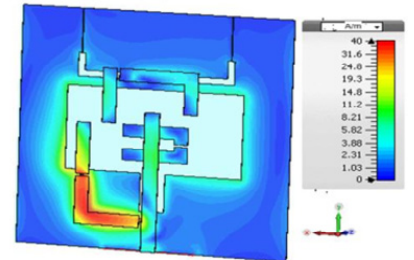

(d)

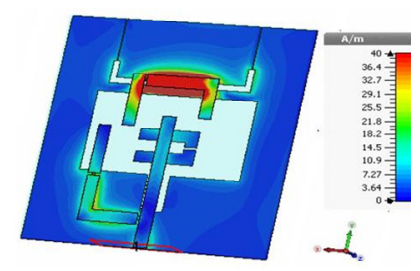

(f)
Fig. 7. Surface current distributions of the proposed antenna in different operating states: (a) State-1, at $3.1 \mathrm{GHz}$, (b) State-2, notch at $3.6 \mathrm{GHz}$, (c) State-3, notch at $5.2 \mathrm{GHz}$, (d) State-5, single band at $3.6 \mathrm{GHz}$, (e) State7 , single band at $3.56 \mathrm{GHz}$, (f) State-7, dual band at $5.2 \mathrm{GHz}$. 


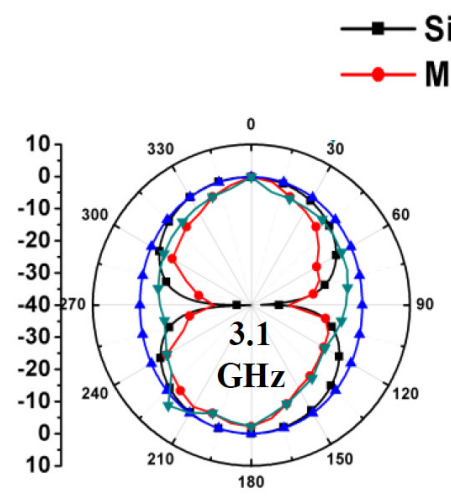

(a)



(d)

\section{$\simeq$ Sim H-plane \\ $\rightarrow$ Meas H-plane}

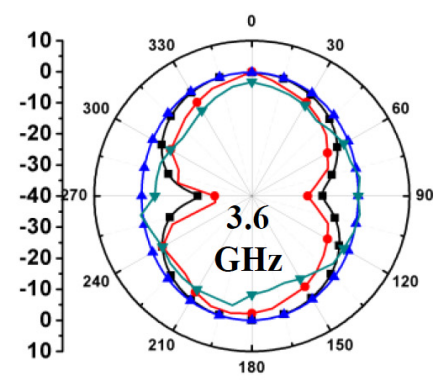

(e)

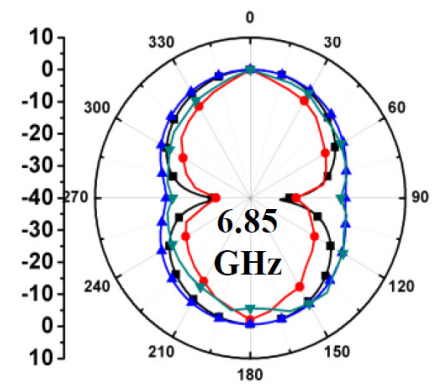

(b)

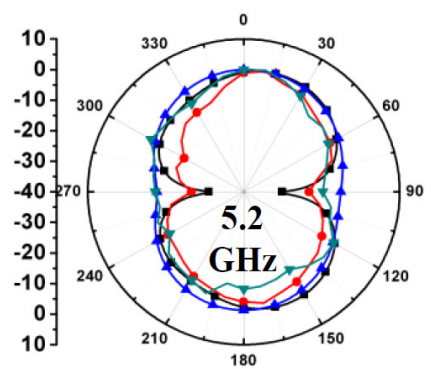

(f)

Fig. 8. Far-field radiation patterns in E-plane and H-plane: (a-c) UWB mode, (d) UWB with notch at $5.2 \mathrm{GHz}$, (e) single radiating mode at $3.6 \mathrm{GHz}$, (f) single radiating mode at $5.2 \mathrm{GHz}$.

\begin{tabular}{|c|c|c|c|c|c|}
\hline Ref & $\begin{array}{l}\text { Size }(\mathrm{L} \times \mathrm{W}) \\
\mathrm{mm}^{2}\end{array}$ & $\varepsilon_{\mathrm{r}} / h$ & $\begin{array}{l}\text { Feeding } \\
\text { Technique }\end{array}$ & $\begin{array}{c}\text { States/ } \\
\text { switches }\end{array}$ & Results/Operations \\
\hline$[15]$ & $32 \times 24$ & $2.65 / 1.6$ & CPW & NA & $\begin{array}{l}\text { UWB band, UWB band with notch either at } 5.5 \text { or } 8.5 \mathrm{GHz} \text { or both } \\
\text { notches }\end{array}$ \\
\hline$[16]$ & $32 \times 24$ & $2.65 / 1.6$ & CPW & $4 / 2$ & $\begin{array}{l}\text { UWB band, UWB band with notch either at } 5.5 \text { or } 7 \mathrm{GHz} \text { or dual notches } \\
\text { at both }\end{array}$ \\
\hline$[17]$ & $55 \times 45$ & $2.2 / 1.6$ & Microstrip & $8 / 3$ & $\begin{array}{c}\text { UWB band, UWB band with notch either at } 2.4 \text { or } 3.5 \text { or } 5.2 \mathrm{GHz} \text { or dual } \\
\text { notches }(2.4 \& 3.5 \text {, or } 2.4 \& 5.2 \text { or } 3.5 \& 5.2) \text { or triple notches at } 2.4,3.5 \\
\text { and } 5.2 \mathrm{GHz}\end{array}$ \\
\hline$[18]$ & $28 \times 12.3$ & $2.56 / 1.6$ & ACS & $2 / 1$ & UWB band, UWB band with notch either at 3.5 or $8.2 \mathrm{GHz}$ or both \\
\hline$[19]$ & $31.2 \times 30$ & $2.56 / 1.6$ & Microstrip & $6 / 4$ & $\begin{array}{l}\text { UWB band, UWB band with notch either at } 6.8 \text { or } 8.7 \mathrm{GHz} \text { or dual } \\
\text { notches }(6 \& 8.7 \text {, or } 5.5 \& 11.5) \text { or triple notches at } 5.5,6.8 \text { and } 11.5 \mathrm{GHz} \text {. }\end{array}$ \\
\hline$[20]$ & $32 \times 24$ & $2.65 / 1.6$ & CPW & $4 / 2$ & UWB band, UWB band with notch either at 3.5 or $8 \mathrm{GHz}$ or both \\
\hline$[21]$ & $58 \times 65.5$ & $2.2 / 1.6$ & Microstrip & $\begin{array}{l}3 / \text { using } \\
\text { physical } \\
\text { rotation }\end{array}$ & $\begin{array}{l}\text { UWB band, reconfigurable with reconfigurable dual band operation either } \\
\text { at } 4 \text { or } 6.65 \mathrm{GHz}\end{array}$ \\
\hline $\begin{array}{l}\text { This } \\
\text { work }\end{array}$ & $40 \times 40$ & $2.55 / 0.77$ & Microstrip & $7 / 5$ & $\begin{array}{l}\text { UWB band, UWB band with reconfigurable notch either at } 3.5 \text { or } 5.2 \\
\text { GHz or dual notches, resonating mode response either at } 3.6 \text { or } 5.2 \mathrm{GHz} \\
\text { or both modes }\end{array}$ \\
\hline
\end{tabular}

CPW: Coplanar Waveguide; ACS: Asymmetric Coplanar Strip-Fed; NA: Not Available

Tab. 3. Comparison with previous reported works. 


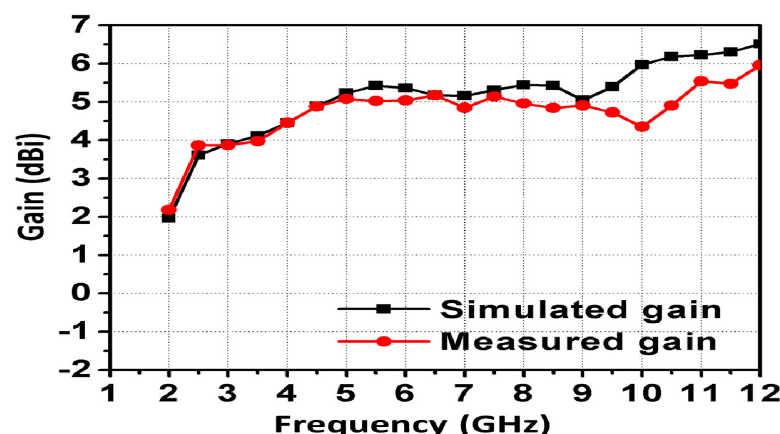

(a)

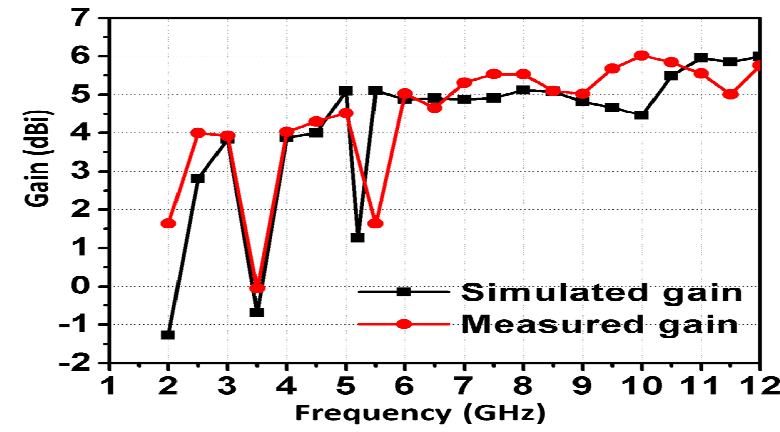

(b)

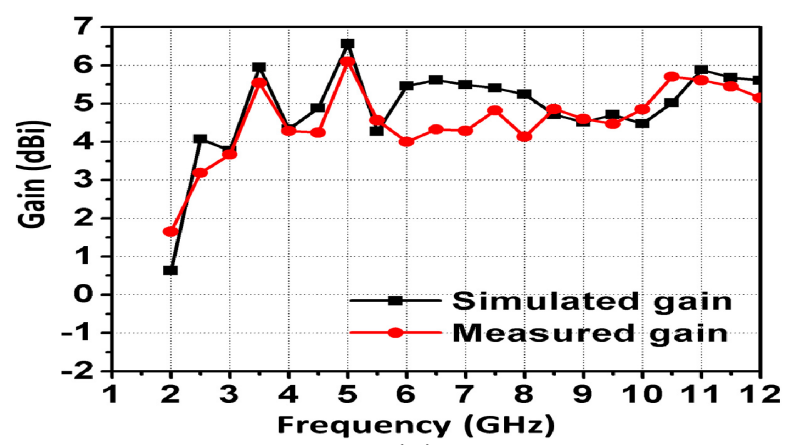

(c)

Fig. 9. Gain of the proposed antenna (a) UWB (State-1), (b) UWB with notches at $3.6 \mathrm{GHz} \& 5.2 \mathrm{GHz}$ (State-5), (c) with parasitic strips for dual band at $3.6 \mathrm{GHz} \&$ 5.2 GHz (State-7).

Simulated and measured far-field radiation patterns in E-plane (yz-plane) and H-plane (zx-plane) at frequency $3.1 \mathrm{GHz}, 5.85 \mathrm{GHz}$ and $10.6 \mathrm{GHz}$ obtained in state-1 (for UWB operation) are shown in Figs. 8(a-c). It is apparent that the antenna provides almost stable and omnidirectional patterns in the entire UWB range. In Fig. 8(d), E-plane and H-plane radiation patterns for UWB operation with notch at $5.2 \mathrm{GHz}$ (state-3) are plotted. It is evident that at $5.2 \mathrm{GHz}$ radiation is suppressed drastically $(-18 \mathrm{~dB})$ from all the direction as desired to avoid any interference in UWB band from WLAN band. Same type of behavior may be expected with notch at $3.6 \mathrm{GHz}$ (state-2). Figures $8(\mathrm{e})$ and (f) show the radiation patterns for dual band reconfigurable antenna resonating at $3.6 \mathrm{GHz}$ (state-5) and $5.2 \mathrm{GHz}$ (state-6). It is clearly shown that parasitic strips contribute for radiation of desired pattern in $3.6 \mathrm{GHz}$ and $5.2 \mathrm{GHz}$ band.
Figure 9 shows simulated and measured gain of the proposed antenna in three states: UWB operation (state-1), UWB with a dual notched (state-4), and dual band operation (state-7).

As shown in Fig. 9(a), a maximum gain of $5 \mathrm{dBi}$ is realized with a variation of $\angle 2 \mathrm{dBi}$ in the whole UWB frequency range. Figure 9 (b) shows the simulated and measured gain of UWB antenna with dual notches, the gain is significantly reduced to $0 \mathrm{dBi}$ and $1.5 \mathrm{dBi}$ at notch frequency $3.6 \mathrm{GHz}$ and $5.2 \mathrm{GHz}$, respectively.

The gain values are not much lower at the notch frequencies as expected. This might be due to parasitic coupling between different elements of the antenna. Figure 9(c) shows the gain of the antenna in the dual band mode. Maximum achieved gain is $5.5 \mathrm{dBi}$ and $6 \mathrm{dBi}$ at frequency of $3.65 \mathrm{GHz}$ and $5.3 \mathrm{GHz}$, respectively. Although the out-of-band gain rejection $(4-5 \mathrm{dBi})$ in state-7 is not as much as good and needs to be improved further.

Comparison of the proposed multifunctional reconfigurable UWB antenna with earlier reported works in similar domain is shown in Tab. 3. It is found that, in addition to UWB operation with multiple notches at 3.6 GHz and $5.2 \mathrm{GHz}$, the proposed antenna could also be used to provide the resonating modes at aforesaid frequencies.

\section{Conclusion}

A new compact size $\left(40 \times 40 \mathrm{~mm}^{2}\right)$ UWB antenna with reconfigurable dual-notched and dual-band characteristics is proposed. Switching mechanism is achieved by using a metal strip to realize ON and OFF states. The proposed antenna could offer seven modes of operation by activating/deactivating five PIN diodes. The proposed antenna is simulated, fabricated and tested for different modes of operation and shows good agreement between measured and simulated return loss, radiation and gain characteristics. The proposed antenna may be an appropriate candidate for UWB operation, UWB operation with WiMAX and WLAN bands rejection capability and for WiMAX/ WLAN applications.

\section{References}

[1] MAK, A. C. K., ROWELL, C. R., MURCH, R. D. et al. Reconfigurable multiband antenna designs for wireless communication devices. IEEE Transactions on Antennas and Propagation, July 2007, vol. 55, no. 7, p. 1919-1928. DOI: 10.1109/TAP.2007.895634

[2] PARK, Y. K., SUNG, Y. A reconfigurable antenna for quad-band mobile handset applications. IEEE Transactions on Antennas and Propagation, June 2012, vol. 60, no. 6, p. 3003-3006. DOI: 10.1109/TAP.2012.2194672 
[3] ZHANG, T., LI, R., JIN, G. et al. A novel multiband planar antenna for GSM/UMTS/LTE/Zigbee/RFID mobile devices. IEEE Transactions on Antennas and Propagation, Nov. 2011, vol. 59, no. 11, p. 4209-4214. DOI: 10.1109/TAP.2011.2164201

[4] LIM, J. H., BACK, G. T. , KO, Y. I., et al. A reconfigurable PIFA using a switchable PIN-diode and a fine-tuning varactor for USPCS/WCDMA/m-WiMAX/WLAN. IEEE Transactions on Antennas and Propagation, July 2010, vol. 58, no. 7, p. 2404 to 2411. DOI: $10.1109 /$ TAP.2010.2048849

[5] LI, Y., ZHANG, Z., ZHENG, J. A compact hepta-band loopinverted $\mathrm{F}$ reconfigurable antenna for mobile phone. IEEE Transactions on Antennas and Propagation. Jan. 2012 vol. 60, no. 1, p. 389-392. DOI: 10.1109/TAP.2011.2167949

[6] LEE, J. H., SUNG, Y. A simple penta-band reconfigurable antenna for mobile device applications. Microwave and Optical Technology Letters, 2014, vol. 56, no. 3, p. 769-774. DOI: $10.1002 /$ mop.28139

[7] Revision of Part 15 of the Commission's Rules Regarding UltraWideband Transmission Systems. FCC, Washington, DC, Tech. Rep. ET-Docket,8, Apr. 2002, p. 1-118. DA/FCC: FCC-10-151

[8] AZIM, R., ISLAM, M. T., MISRAN, N. Compact tapered-shape slot antenna for UWB applications. IEEE Antennas and Wireless Propagation Letters, 2011, vol. 10, p. 1190-1193. DOI: 10.1109/LAWP.2011.2172181

[9] KAHRIZI, M., SARKAR, T. K., MARICEVIC, Z. A. Analysis of a wide radiating slot in the ground plane of a microstrip line. IEEE Transactions on Microwave Theory and Techniques, Jan. 1993, vol. 41, no. 1, p. 29-37. DOI: 10.1109/22.210226

[10] TASOUJI, N., NOURINIA, J., GHOBADI, C., et al. A novel printed UWB slot antenna with reconfigurable band-notch characteristics. IEEE Antennas and Wireless Propagation Letters, 2013, vol. 12, p. 922-925. DOI: 10.1109/LAWP.2013.2273452

[11] SRIVASTAVA, G., DWARI, S., KANAUJIA, B. K. A compact UWB antenna with reconfigurable dual notch bands. Microwave and Optical Technology Letters, 2015, vol. 57, no. 12, p. 2737 to 2742. DOI: $10.1002 /$ mop. 29424

[12] VALIZADE, A., GHOBADI, CH., NOURINIA, J., et al. A novel design of reconfigurable slot antenna with switchable band notch and multiresonance functions for UWB applications. IEEE Antennas and Wireless Propagation Letters, 2012 vol. 11, p. 1166-1169. DOI: 10.1109/LAWP.2012.2218271

[13] BADAMCHI, B., NOURINIA, J., GHOBADI, C., et al. Design of compact reconfigurable ultra-wideband slotantenna with switchable single/dual band notchfunctions. IET Microwave, Antennas and Propagation, 2013, vol. 8, no. 8, p. 541-548. DOI: 10.1049/iet-map.2013.0311

[14] CHEN, W. S., LEE, B. Y., CHANG, P. Y. A compact microstripline-fed slot antenna with dual-band notched for WiMAX operation. Progress In Electromagnetics Research C, 2010, vol. 16, p. 13-23. DOI: 10.2528/PIERC10080803
[15] LI, Y., LI, W., YU, W. A switchable UWB slot antenna using SISHSIR and SIS-SIR for multi-mode wireless communications applications. Applied Computational Electromagnetics Society Journal, 2012, vol. 27, no. 4, p. 340-351.

[16] LI, Y., LI, W., YE, Q. A reconfigurable wide slot antenna integrated with sirs for UWB/multiband communication applications. Microwave and Optical Technology Letters, 2013, vol. 55, no. 1, p. 52-55. DOI: 10.1002/mop.27253

[17] AL-HUSSEINI, M., RAMADAN, A., EL-HAJJ, A. et al. Design based on complementary split-ring resonators of an antenna with controllable band notches for UWB cognitive radio applications. In Proceedings of the IEEE International Symposium on Antennas and Propagation and USNC/URSI National Radio Science Meeting (APSURSI '11), July 2011, p. 1120-1122. DOI: 10.1109/APS.2011.5996479

[18] LI, Y., LI, W., YE, Q. Miniaturization of asymmetric coplanar strip-fed staircase ultrawideband antenna with reconfigurable notch band. Microwave and Optical Technology Letters, vol. 55, p. 1467-1470. DOI: $10.1002 /$ mop. 27634

[19] LI, Y., LI, W., YE, Q. A reconfigurable triple-notch-band antenna integrated with defected microstrip structure band-stop filter for ultra-wideband cognitive radio applications. International Journal of Antennas and Propagation, 2013, 13 p. DOI: $10.1155 / 2013 / 472645$

[20] LI, Y., LI, W., MITTRA, R. A compact CPW-fed circular slot antenna with reconfigurable dual band-notch characteristics for UWB communication applications. Microwave and Optical Technology Letters, 2014, vol. 56, no. 2, p. 465-468. DOI: 10.1002/mop. 28087

[21] TAWK, Y., CHRISTOdOUlOU, C. G. A new reconfigurable antenna design for cognitive radio. IEEE Antennas and Wireless Propagation Letters, 2009, vol. 8, p. 1378-1381. DOI: 10.1109/LAWP.2009.2039461

\section{About the Authors ...}

Asha VERMA received her Master of Technology (M.Tech.) from PDPM-IIITDM Jabalpur, India, in 2015. Her research interests include UWB technologies and reconfigurable antennas.

Manoj S. PARIHAR received his Ph.D. from the Indian Institute of Technology Delhi, India, in 2012. Presently, he is working as an assistant professor in PDPM-IIITDM Jabalpur, India. His current research interests are reconfigurable circuits, microwave integrated circuits, EMC/EMI, RFID, RF MEMS, RF energy harvesting, and UWB technology. 